\title{
Understanding Ehrlichia canis Infections in Dogs of Costa Rica: Hematological Findings and Indicative Clinical Signs
}

\author{
Alexander V. Barrantes-Gonzálezi ${ }^{*}$, Ana E. Jiménez-Rocha², Juan José Romero-Zuñiga1 , Gaby Dolz1 \\ ${ }^{1}$ Programa de Investigación en Medicina Poblacional, Escuela de Medicina Veterinaria, Universidad Nacional, Heredia, Costa Rica \\ ${ }^{2}$ Laboratorio de Parasitología, Escuela de Medicina Veterinaria, Universidad Nacional, Heredia, Costa Rica \\ Email:*avbarrantesgonzalez@gmail.com
}

How to cite this paper: Barrantes-González, A.V., Jiménez-Rocha, A.E., Romero-Zuñiga, J.J. and Dolz, G. (2016) Understanding Ehrlichia canis Infections in Dogs of Costa Rica: Hematological Findings and Indicative Clinical Signs. Open Journal of Veterinary Medicine, 6, 163-175.

http://dx.doi.org/10.4236/ojvm.2016.611020

Received: September 22, 2016

Accepted: November 27, 2016

Published: November 30, 2016

Copyright (๑) 2016 by authors and Scientific Research Publishing Inc. This work is licensed under the Creative Commons Attribution International License (CC BY 4.0).

http://creativecommons.org/licenses/by/4.0/

\section{Abstract}

Background: A cross-sectional study combining different serological and molecular techniques for the detection of Ehrlichia canis in dogs was carried out to determine hemopathological findings and suggestive clinical signs associated with acute, subclinical and chronic infections in the dog population of Costa Rica. Objectives: The present study describes and analyzes, in a more representative sampling frame, the clinical and hematological presentation of $E$. canis infection in dogs of Costa Rica in all its clinical stages. Methods: A descriptive analysis of the clinical signs was performed from a 441-dog sample. Serological and molecular techniques for the detection of Ehrlichia canis in dogs were applied. One and two-way ANOVA were carried out to determine the effect of the infection status on the hematological parameters. Results: A total of $0.7 \%$ (3/407) dogs were found with acute (seronegative but PCR positive), 29.7\% (121/407) with subclinical (seropositive and PCR negative), and $2.5 \%$ (10/407) with chronic (seropositive and PCR positive) E. canis infections. Significant hemopathological findings were determined in dogs with acute (thrombocytosis), subclinical and chronic (anemia, thrombocytopenia, leukopenia) E. canis infections. Conclusions: Future studies must determine if dogs with subclinical $E$. canis infections eliminated the agent without any medication, or if they continue to be persistently infected, and will develop the chronic disease at some point in their lives.

\section{Keywords}

Ehrlichiosis, Epidemiology, Hematopathology, Infectious Disease, Clinical Pathology 


\section{Introduction}

Ehrlichiosis is caused by bacteria classified within the group of the alpha-proteobacteria, order Rickettsiales, family Anaplasmataceae, genus Ehrlichia [1]. This genus consists of obligate intracellular Gram-negative bacteria that mainly infect leukocytes such as monocytes, macrophages, and granulocytes [2].

Monocytotropic canine ehrlichiosis is caused by Ehrlichia canis, which is found in the form of morulae in the cytoplasm of lymphocytes, monocytes, and macrophages [3]. The incubation period ranges from 8 to 20 days [4] followed by the acute, subclinical, and chronic stages of the disease.

The most important clinical signs of infection are fever, depression, lethargy, anorexia, weight loss, cardiac arrhythmias, hemorrhagic diathesis, central nervous system signs, lymphadenomegaly, splenomegaly, polyarthritis, uveitis anterior, ocular signs and blindness from retinal edema or bleeding and detachment. The most significant laboratory findings are thrombocytopenia, anemia, leukopenia, hyperglobulinemia, proteinuria, lymphocytic pleocytosis, and bone marrow plasmacytosis [4].

The acute phase lasts between two to four weeks [5] and is characterized by fever, weight loss, anorexia, depression, lymphadenomegaly, splenomegaly, vasculitis, and ocular and musculoskeletal signs [6] [7] [8]. Thrombocytopenia is the most common abnormality in naturally or experimentally infected dogs in this phase of the disease [8].

The subclinical phase has a duration that varies from months to years [5] [9]. Dogs in this stage are known to be carriers of $E$. canis and remain clinically healthy for months or years [10] until they spontaneously recover from infection or develop severe illness. During this phase, the animal may show high anti-E. canis antibody titers [11], persistent thrombocytopenia, and leucopenia with no other clinical signs [9] [10] [11]. Generally, bacterial DNA is not found in blood samples in this phase; spleen and bone marrow are the most appropriate tissues to analyze [3] [12]. Severe pancytopenia, hemorrhagic diathesis, and organism debilitation may characterize the chronic phase [5]. Although the conditions that can lead the animal to this stage are not totally clear, it has been suggested that factors such as breed, immune system deficiency, stress conditions, co-infections, virulence of the strain, and the geographical region could have some influence on the outcome of infection [10].

E. canis was reported for the first time in dogs of Costa Rica by Meneses [13]. Romero et al. [14] analyzed blood samples from dogs with clinical signs or suspected of suffering ehrlichiosis, and found highly significant differences in hematocrit and hemoglobin values between PCR positive and negative dogs. In this population, $26.6 \%$ (8/30) were determined to have acute (seronegative and PCR positive) E. canis infections, while $20.0 \%$ (6/30) had subclinical (seropositive and PCR negative) and 6.6\% (2/30) had chronic (seropositive and PCR positive) E. canis infections [14]. Another study carried out in four regions of Costa Rica found 58.0\% (29/50) of dogs with subclinical E. canis infections [15]. The present study describes and analyzes, in a more representative sampling frame, the clinical and hematological presentation of E. canis infection in dogs of Costa Rica. 


\section{Materials and Methods}

\subsection{Study Design, Sample Size and Analyzed Population}

A cross-sectional, observational, descriptive study was conducted to determine the presence of, or exposure to, Ehrlichia spp. in blood samples from dogs, using molecular and serological assays, respectively. The total sample size was estimated to be 385 individuals (50\% prevalence, $95 \%$ confidence) for a population of more than 40,000 dogs, calculated using Win Episcope 2.0. More details of the population studied, sampling methodology and period of study are described in Barrantes-González et al. [16].

\subsection{Interview, Clinical Examination, and Sampling}

Each owner was interviewed to obtain information about the place of origin, tick infestation, treatment of ticks, and signs suggestive of ehrlichiosis (fever, weight loss, depression, epistaxis, petechiae, ecchymosis, hematuria, dyspnea, cough, lymphadenomegaly, ataxia, diarrhea and scrotal edema), observed by the owners at some point in the lives of their pets. Also, other important information was obtained like if their veterinarian had suspected ehrlichiosis in the past, if the dog was treated because of this suspicion, and finally the medications used to treat those dogs was investigated. Veterinarians made sure to ask the owners in an appropriate fashion, adapting their vocabulary to the educational level of the respondent, to ensure that the questions were understood correctly. Clinical examination was performed to determine attitude (weak, depressed, docile, alert, nervous, aggressive), capillary refill time ( $>2 \mathrm{~s}$ was considered as delayed), color of mucous membranes (very pale, pale, pink, icteric), rectal temperature $\left(\geq 39.5^{\circ} \mathrm{C}\right.$ was considered as feverish) and clinical signs suggestive of ehrlichiosis (weight loss, epistaxis, petechiae, ecchymosis, hematuria, dyspnea, cough, lymphadenomegaly, ataxia, lameness, diarrhea and scrotal edema). Dogs that were treated with doxycycline were recorded. From stray dogs living in recreational parks, consent from the administration was obtained. Only clinical exam and sampling was performed.

\subsection{Blood Analysis}

The HETTICH ${ }^{\varpi}$ microcentrifuge $(5$ minutes $\times 18,600 \mathrm{~g}$ ) and DAMON/IEC hematocrit reader were used to determine hematocrit values. Blood smears were stained with Giemsa as described by Cowell et al. [17] to determine complete blood count (CBC).

\subsection{Serological Analysis}

Two commercial techniques were used to detect antibodies against E. canis, "Speed Ehrli" Virbac, an Immunochromatography Membrane Assay (IMA) (Bio Veto Test, Rome, Italy; sensitivity $87 \%$, specificity $95 \%$ ) and "E. canis and $A$. phagocytophilum Canine IgG Antibody Kit”, an Indirect Immunofluorescence Assay (IFA) (Fuller Laboratories, California, USA; sensitivity and specificity 100\%). The methodologies recommended by the manufacturers were used. Sera were analyzed in IFA only in one dilution (1:80). Sera that exhibited fluorescence in 1:80 dilution were considered positive in IFA. Results of the two tests were compared. "Parallel testing" methodology was used 
to determine the seroprevalence.

\subsection{Molecular Analysis}

Extraction of DNA from blood samples was performed with the "Wizard Genomic" assay (Promega ${ }^{\oplus}$, Wisconsin, USA). The conventional nested PCR was carried out as described by Romero et al. [14]: Primers ECC and ECB were used in the first round to amplify a segment of the 16S rRNA of Ehrlichia spp. The second PCR was carried out using primers HE3 and ECAN5 for E. canis, primers HE3 and HE1 for E. chaffeensis, and HE3 and EE5 for amplifying E. ewingii. PCR products (389 to $396 \mathrm{bp}$ ) were purified using the QIAquick kit (QIAGEN $\left.{ }^{\circledR}\right)$, proceeding according to the manufacturer's instructions, and sent to Macrogen (Seoul, Korea) for sequencing. Further detailed molecular analysis methodology is described in Barrantes-González et al. [16].

\subsection{Statistical Analysis}

Data obtained from the interview, clinical examination and results of diagnostic tests (serology and PCR) were entered a digital database. A descriptive analysis of the results through measures of central tendency (mean), measures of dispersion (standard deviation and $95 \%$ confidence interval) and frequency (\%) by factors was performed. The presence or absence of $E$. canis antigen and presence or absence of antibodies against $E$. canis was determined, and frequency distributions of positive and negative results were determined. One-way ANOVA was performed to determine the difference of means between positive and negative (serology and molecular detection separately) groups for each hematological variable. Two-way ANOVA was carried out to assess the difference of means between positive and negative groups per infection status (non-infected, acute, subclinical and chronic) to E. canis. The statistical analysis was performed using STATA IC 13 (Stata Corp., USA).

\section{Results}

Of the total of dogs $(\mathrm{n}=441)$ that participated in the study, 399 had owners, and it was possible to conduct an owner interview, while 42 (9.5\%) dogs were residents of the parks and had no known owner. A total of $55.9 \%$ of the owners had observed ticks on their pets, only $2.0 \%$ (9/441) of the dogs were diagnosed previously by a veterinarian with ehrlichiosis; $77.8 \%$ of them had been treated (28.6\% with doxycycline and $71.4 \%$ did not remember the name of the medication) to: "ehrlichiosis; seven dogs had been treated ( 2 with doxycycline, and 5 did not remember the name of the medication), and..." in $3.6 \%$ of cases $(16$ dogs $)$ the veterinarians suspected that the pets had ehrlichiosis. Clinical signs suggestive of ehrlichiosis observed by the owners at some point in the lives of their pets were: bleeding (17.0\%), petechiae $(9.5 \%)$, weight loss (4.5\%), and hematuria (1.8\%) (Table 1).

Clinical examination encountered abnormalities in only a minority of the dogs, such as attitude (weak $0.2 \%$, depressed $0.7 \%$, docile $16.1 \%$ ), capillary refill time $>2$ seconds (5.2\%), mucous membranes (very pale $1.1 \%$, pale $11.1 \%$ ), and rectal temperatures $\geq$ 
$39.5^{\circ} \mathrm{C}(19.5 \%)$. Clinical abnormalities included weight loss (4.5\%), lymphadenomegaly $(2.0 \%)$, petechiae $(1.6 \%)$, cough $(0.9 \%)$, scrotal edema $(0.9 \%)$, ataxia $(0.5 \%)$ and hematuria $(0.2 \%)$ (Table 1$)$.

Hematocrit and complete blood count $(\mathrm{CBC})$ results from the total dog sample are shown in Table 2.

Analysis of hematological values of dogs that were seropositive and seronegative to $E$. canis determined a highly significant difference $(p<0.001)$ in mean hematocrit, hemoglobin and platelet count values, and a weak difference $(p=0.05-0.10)$ in mean corpuscular hemoglobin concentration (MCHC), white blood count (WBC), specifically, lymphocytes and monocytes values. In all cases, mean values for all the above variables were lower in seropositive than in seronegative dogs.

Also, analysis of dogs that were PCR positive and PCR negative to E. canis determined a highly significant difference in the mean values of lymphocytes and basophils, and a weak difference in the hematocrit and mean values between PCR positive and PCR negative dogs. In all cases, mean values for all the above variables were lower in positive than in negative dogs (Table 2).

Table 1. Clinical signs observed by the owner in the past and clinical signs observed by the veterinarian at the moment of sampling.

\begin{tabular}{|c|c|c|}
\hline Variable & $\begin{array}{l}\text { Observed by owner } \\
\#(\%) \mathrm{n}=399\end{array}$ & $\begin{array}{c}\text { Observed by veterinarian at } \\
\text { sampling \# }(\%) \mathrm{n}=441\end{array}$ \\
\hline Fever & 0 & $86(19.5)$ \\
\hline \multicolumn{3}{|l|}{ Attitude } \\
\hline Docile & - & $71(16.1)$ \\
\hline Depressed & - & $3(0.7)$ \\
\hline Weak & - & $1(0.2)$ \\
\hline \multicolumn{3}{|l|}{ Mucous membranes } \\
\hline Pale & - & $49(11.1)$ \\
\hline Very pale & - & $5(1.1)$ \\
\hline Capillary refill time $>2 \mathrm{~s}$ & - & $23(5.2)$ \\
\hline Weight loss & $18(4.5)$ & $21(4.5)$ \\
\hline Lymphadenomegaly & 0 & $9(2.0)$ \\
\hline Petechiae & $39(9.5)$ & $7(1.6)$ \\
\hline Cough & 0 & $4(0.9)$ \\
\hline Ataxia & 0 & $2(0.5)$ \\
\hline Hematuria & $7(1.8)$ & $1(0.2)$ \\
\hline Bleeding & $68(17.0)$ & $0(0)$ \\
\hline Ecchymosis & $0(0)$ & $0(0)$ \\
\hline Dyspnea & $0(0)$ & $0(0)$ \\
\hline Lameness & $0(0)$ & $0(0)$ \\
\hline Diarrhea & $0(0)$ & $0(0)$ \\
\hline Scrotal edema & $0(0)$ & $0(0)$ \\
\hline
\end{tabular}




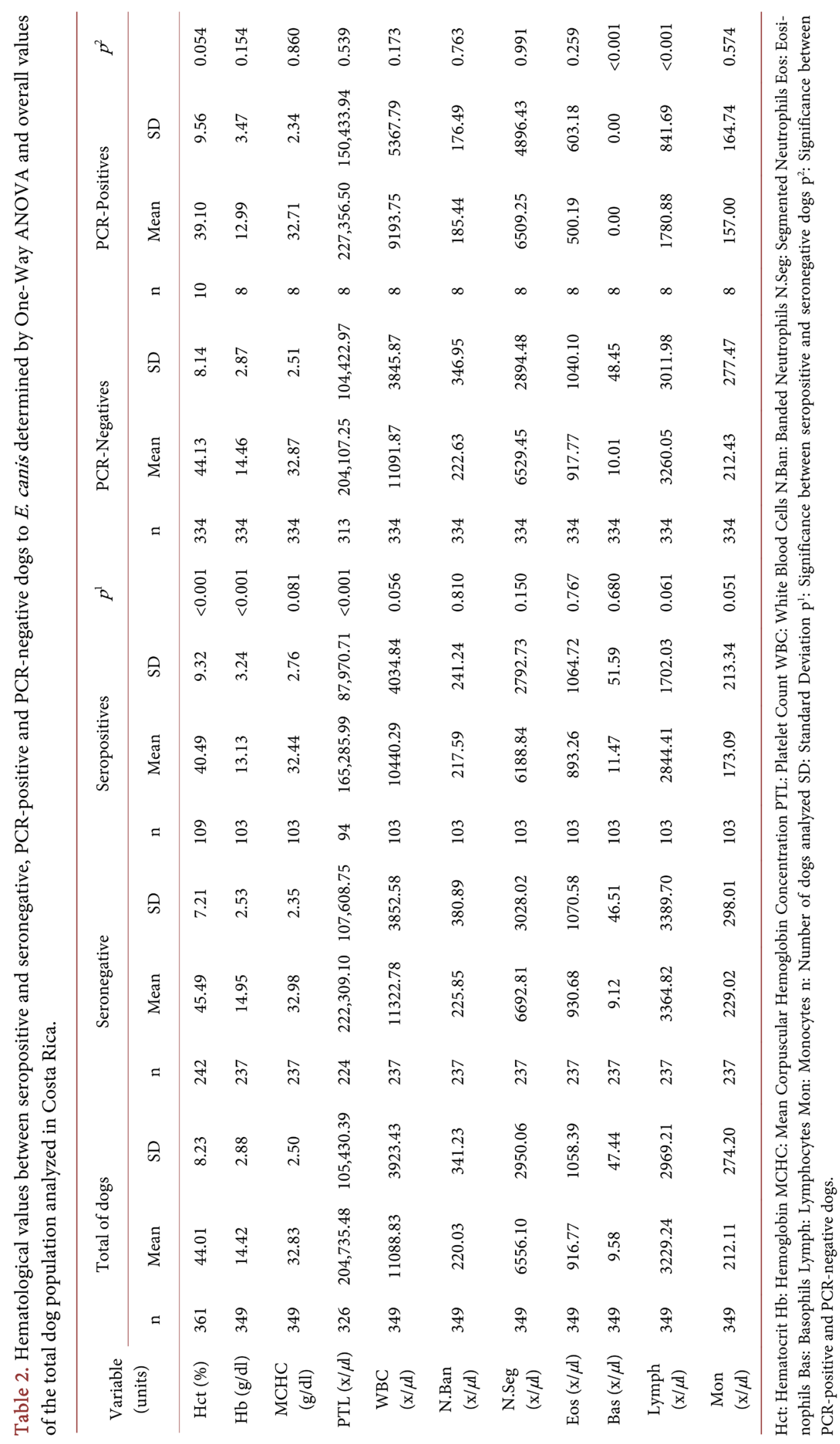


Using parallel testing methodology, 32.1\% (131/408) of the dogs were determined as seropositive to E. canis. $23.2 \%(95 / 408)$ by IFA and $30.0 \%$ (121/403) by IMA. The DNA of $E$. canis was detected in $3.2 \%$ (13/407) of the analyzed blood samples, DNA of $E$. chaffeensis and DNA of E. ewingii was not found. A total of 10 (77.0\%) E. canis PCR positive dogs showed also antibodies against $E$. canis.

The results of serological and molecular tests found $29.7 \%$ (121/407) of dogs with subclinical infection (seropositive and PCR-negative), 2.5\% (10/407) with chronic infection (seropositive and PCR-positive), and only $0.7 \%$ (3/407) with acute E. canis infection (seronegative and PCR-positive).

Suggestive clinical signs reported by the owners of dogs with subclinical E. canis infection were bleeding (26/121), petechiae (8/121), weight loss (9/121), hematuria (2/ 121). Clinical signs detected by the veterinarians at the time of sampling of these dogs were fever (43/121), depressive attitude (1/121), pale mucous membranes (21/121), very pale mucous membranes (2/121), bad body condition (72/121), very bad body condition (38/121), petechiae (3/121), lymphadenomegaly (3/121), and ataxia (1/121).

Two-way ANOVA analysis of these seropositive but PCR-negative dogs showed significant differences $(p<0.05)$ in mean hematocrit, hemoglobin and platelet count and weak significant difference $(p<0.10)$ in mean WBC count values. The group with subclinical infection showed always lower values than non-infected dogs in all the above values, and platelet values were lower than in dogs with acute infection $(p<$ $0.05)$, but the mean hematocrit and WBC count $(p=0.05-0.10)$ were higher than in dogs with chronic infections (Table 3(a) and Table 3(b)).

Suggestive clinical signs reported by the owners of dogs suffering chronic E. canis infection were bleeding (2/10) and petechiae (2/10), whereas the veterinarians detected, at the time of sampling in this group, dogs with depressive attitude (1/10) and very pale mucous membranes $(4 / 10)$.

Comparison of hematological values of these seropositive and PCR-positive dogs with non-infected dogs determined significant differences $(\mathrm{p}<0.05)$ in mean hematocrit, hemoglobin and platelet count values and weak significant differences $(\mathrm{p}<0.05$ $0.10)$ in mean WBC count values. Mean values were always lower in the group of dogs with chronic E. canis infection compared to non-infected dogs. Mean hematocrit and WBC values were the lowest from all groups and platelet count values were lower compared with dogs with acute infection (Table 3(a) and Table 3(b)).

Suggestive clinical signs reported by the owner of one dog suffering acute E. canis infection was petechiae (1/3), and clinical signs detected by the veterinarians at the time of sampling in this group of dogs was fever (2/3).

Analysis of dogs with acute infections (seronegative but PCR-positives) showed significant differences $(p<0.05)$ in mean platelet count values when compared to noninfected dogs. Hematocrit and hemoglobin mean values were higher than in dogs with chronic infections $(p<0.05)$. Mean platelet count values were the highest of all groups $(p<0.05)$ (Table 3(a) and Table 3(b)). 
Table 3. (a) Hematological values for red blood indices and platelet counts among non-infected (1), acute (2), subclinical (3) and chronic (4) E. canis infected dogs determined by Two-Way ANOVA test; (b) Hematological values for white blood cells among non-infected (1), acute (2), subclinical (3) and chronic (4) E. canis infected dogs determined by Two-Way ANOVA test.

(a)

\begin{tabular}{|c|c|c|c|c|c|c|c|c|c|}
\hline \multirow{2}{*}{$\begin{array}{l}\text { Variable } \\
\text { (units) }\end{array}$} & \multirow[t]{2}{*}{ Group } & \multirow[t]{2}{*}{$\mathrm{n}$} & \multirow[t]{2}{*}{ Mean } & \multirow[t]{2}{*}{$\mathrm{SD}$} & \multicolumn{2}{|c|}{$95 \% \mathrm{CI}$} & \multirow[t]{2}{*}{ SSD } & \multicolumn{2}{|c|}{ ANOVA results } \\
\hline & & & & & LL & UL & & F value & $p$ value \\
\hline \multirow{4}{*}{$\begin{array}{c}\text { Hematocrit } \\
(\%)\end{array}$} & 1 & 233 & 45.40 & 7.21 & 44.38 & 46.42 & $a$ & 11.053 & $0.000^{\mathbf{0}}$ \\
\hline & 2 & 3 & 49.00 & 2.00 & 40.04 & 57.96 & $a, b$ & 948.616 & $0.000^{\circ}$ \\
\hline & 3 & 100 & 40.93 & 9.34 & 39.39 & 42.48 & $b^{*}$ & 11.345 & $0.000^{\boldsymbol{\Theta}}$ \\
\hline & 4 & 7 & 34.86 & 8.11 & 28.99 & 40.72 & $c^{*}$ & 0.200 & $0.655^{\oplus}$ \\
\hline \multirow{6}{*}{$\begin{array}{l}\text { Hemoglobin } \\
\qquad(\mathrm{g} / \mathrm{dl})\end{array}$} & & & & & & & & 3.065 & $0.081^{\boldsymbol{\ominus}}$ \\
\hline & 1 & 228 & 14.95 & 2.55 & 14.59 & 15.31 & $a$ & 11.340 & $0.000^{\mathbf{0}}$ \\
\hline & 2 & 3 & 16.20 & 1.91 & 13.05 & 19.35 & $a, b$ & 731.092 & $0.000^{\circ}$ \\
\hline & 3 & 96 & 13.25 & 3.26 & 12.70 & 13.81 & $b, c$ & 11.099 & $0.001^{\circledR}$ \\
\hline & 4 & 5 & 11.06 & 2.62 & 8.62 & 13.50 & $c$ & 0.210 & $0.647^{\boldsymbol{\oplus}}$ \\
\hline & & & & & & & & 2.824 & $0.094^{\circledR}$ \\
\hline \multirow{4}{*}{ MCHC (g/dl) } & 1 & 228 & 33.03 & 2.34 & 32.71 & 33.36 & $a$ & 1.296 & $0.276^{\mathbf{0}}$ \\
\hline & 2 & 3 & 33.01 & 2.93 & 30.18 & 35.84 & $a, b$ & & \\
\hline & 3 & 96 & 32.44 & 2.80 & 31.95 & 32.94 & $b$ & & \\
\hline & 4 & 5 & 32.53 & 2.29 & 30.34 & 34.72 & $a, b$ & & \\
\hline \multirow{5}{*}{ Platelets $(\mathrm{x} / \mu \mathrm{l})$} & 1 & 216 & $220,608.27$ & $106,388.04$ & $207,014.94$ & $234,201.60$ & $a$ & 9.186 & $0.000^{\mathbf{0}}$ \\
\hline & 2 & 3 & $368,835.00$ & $132,175.55$ & $253,491.77$ & $484,178.23$ & $b$ & 142.589 & $0.000^{\circ}$ \\
\hline & 3 & 88 & $166,567.82$ & $88,521.27$ & $145,391.15$ & $187,744.50$ & $c$ & 13.888 & $0.000^{\boldsymbol{\top}}$ \\
\hline & 4 & 5 & $142,469.40$ & $82,756.02$ & $53,124.92$ & $231,813.88$ & $c$ & 2.722 & $0.100^{\bullet}$ \\
\hline & & & & & & & & 5.245 & $0.023^{\circ}$ \\
\hline
\end{tabular}

Two-way ANOVA results, when the model was significant $(\mathrm{p}<0.10)$, must be read in the following order: $\mathbf{0}$ corrected model, 2 intersection, $\boldsymbol{3}$ serology effect, $\mathbf{4}$ molecular detection effect and $\mathbf{6}$ interaction; otherwise only the corrected model data was included 1: Non-infected dogs 2: Acute infection 3: Subclinical Infection 4: Chronic infection MCHC: Mean Corpuscular Hemoglobin Concentration: Number of individuals SD: Standard Deviation 95\% CI: 95\% Confidence Interval SSD: Statistically Significant Mean Differences (means bearing different letters differ significantly $(\mathrm{p}<0.05)$; letters bearing ${ }^{*}$ or + differ by $\mathrm{p}=0.05-0.10$ exclusively from those that also bear the same symbol, otherwise $\mathrm{p}<0.05$. 


\section{(b)}

\begin{tabular}{|c|c|c|c|c|c|c|c|c|c|}
\hline \multirow{2}{*}{ Variable (units) } & \multirow{2}{*}{ Group } & \multirow{2}{*}{$\mathrm{n}$} & \multirow{2}{*}{ Mean } & \multirow{2}{*}{$\mathrm{SD}$} & \multicolumn{2}{|c|}{$95 \% \mathrm{CI}$} & \multirow{2}{*}{ SSD } & \multicolumn{2}{|c|}{ ANOVA results } \\
\hline & & & & & LL & UL & & F value & $p$ value \\
\hline \multirow{4}{*}{$\mathrm{WBC}(\mathrm{x} / \mu \mathrm{l})$} & 1 & 228 & 11311.62 & 3830.90 & 10808.73 & 11814.52 & $a^{*}$ & 2.558 & $0.055^{\mathbf{0}}$ \\
\hline & 2 & 3 & 11983.33 & 7938.25 & 7599.20 & 16367.47 & $a, b, c$ & 208.582 & $0.000^{\circ}$ \\
\hline & 3 & 96 & 10455.16 & 3827.54 & 9684.15 & 11226.16 & $b^{*+}$ & 3.466 & $0.064^{\circledR}$ \\
\hline & 4 & 5 & 7520.00 & 3094.67 & 4124.07 & 10915.93 & $c^{+}$ & 0.627 & $0.429^{\bullet}$ \\
\hline \multirow{5}{*}{$\begin{array}{c}\text { Banded } \\
\text { Neutrophils } \\
(\mathrm{x} / \mu \mathrm{l})\end{array}$} & & & & & & & & 1.593 & $0.208^{\ominus}$ \\
\hline & 1 & 228 & 229.73 & 386.87 & 184.34 & 275.12 & $a$ & 0.082 & $0.970^{\mathbf{0}}$ \\
\hline & 2 & 3 & 224.33 & 231.29 & -171.38 & 620.05 & $a$ & & \\
\hline & 3 & 96 & 217.83 & 244.78 & 148.24 & 287.42 & $a$ & & \\
\hline & 4 & 5 & 162.10 & 162.10 & -144.42 & 468.62 & $a$ & & \\
\hline \multirow{4}{*}{$\begin{array}{l}\text { Segmented } \\
\text { Neutrophils } \\
\quad(\mathrm{x} / \mu \mathrm{l})\end{array}$} & 1 & 228 & 6652.79 & 2973.71 & 6268.07 & 7037.52 & $a$ & 1.430 & $0.234^{\mathbf{0}}$ \\
\hline & 2 & 3 & 8662.67 & 7153.36 & 5308.72 & 12016.62 & $a$ & & \\
\hline & 3 & 96 & 6181.08 & 2731.18 & 5591.45 & 6770.92 & $a$ & & \\
\hline & 4 & 5 & 5217.20 & 3287.30 & 2619.24 & 7815.16 & $a$ & & \\
\hline \multirow{4}{*}{$\begin{array}{l}\text { Eosinophils } \\
\qquad(\mathrm{x} / \mu \mathrm{l})\end{array}$} & 1 & 228 & 940.20 & 1086.72 & 804.28 & 1076.13 & $a$ & 0.745 & $0.526^{\mathbf{0}}$ \\
\hline & 2 & 3 & 897.00 & 870.26 & -287.98 & 2081.98 & $a, b$ & & \\
\hline & 3 & 96 & 874.18 & 958.84 & 665.78 & 1082.57 & $a$ & & \\
\hline & 4 & 5 & 262.10 & 262.80 & -655.78 & 1179.98 & $b$ & & \\
\hline \multirow{4}{*}{ Basophils $(\mathrm{x} / \mu \mathrm{l})$} & 1 & 228 & 9.48 & 153.30 & 3.14 & 15.83 & $a$ & 0.185 & $0.906^{\mathbf{0}}$ \\
\hline & 2 & 3 & - & - & - & - & & & \\
\hline & 3 & 96 & 12.18 & 53.40 & 2.45 & 21.90 & $a$ & & \\
\hline & 4 & 5 & - & - & - & - & & & \\
\hline \multirow{4}{*}{$\begin{array}{l}\text { Lymphocytes } \\
\qquad(\mathrm{x} / \mu \mathrm{l})\end{array}$} & 1 & 228 & 3387.68 & 3438.21 & 2996.41 & 3778.95 & $a^{*}$ & 1.259 & $0.289^{\circ}$ \\
\hline & 2 & 3 & 2041.00 & 542.13 & -1370.00 & 5452.00 & $b$ & & \\
\hline & 3 & 96 & 2885.51 & 1705.93 & 2285.64 & 3485.37 & $b^{*}$ & & \\
\hline & 4 & 5 & 1624.80 & 1005.79 & -1017.34 & 4266.95 & $b$ & & \\
\hline \multirow{4}{*}{$\begin{array}{l}\text { Monocytes } \\
\qquad(\mathrm{x} / \mu \mathrm{l})\end{array}$} & 1 & 228 & 230.08 & 301.69 & 193.98 & 266.17 & $a$ & 1.140 & $0.333^{\mathbf{0}}$ \\
\hline & 2 & 3 & 158.3 & 139.66 & -156.32 & 472.98 & $a, b$ & & \\
\hline & 3 & 96 & 168.6 & 214.10 & 155.55 & 226.22 & $b$ & & \\
\hline & 4 & 5 & 156.4 & 194.26 & -87.53 & 399.93 & $a, b$ & & \\
\hline
\end{tabular}

Two-way ANOVA results, when the model was significant $(\mathrm{p}<0.10)$, must be read in the following order: $\mathbf{0}$ corrected model, $\boldsymbol{2}$ intersection, $\mathbf{3}$ serology effect, $\mathbf{4}$ molecular detection effect and $\mathbf{6}$ interaction; otherwise only the corrected model data were included 1: Non-infected dogs 2: Acute infection 3: Past infection 4: Persistent infection WBC: White Blood Cells n: Number of individuals SD: Standard Deviation 95\%. 
Analysis using two-way ANOVA did not determine any association with changes in white blood cell differential values and serology or molecular detection status, nor did it determine any significant difference in white blood cell values between infection stages (Table 3(b)).

\section{Discussion}

Suggestive clinical signs reported by the owners of dogs suffering subclinical infections (bleeding, petechiae, weight loss, and hematuria) were in accordance with reports in the literature of dogs presenting acute or chronic E. canis infection [18]. Clinical signs detected by the veterinarians at the time of sampling (fever, depressive attitude, pale or very pale mucous membranes, bad or very bad body condition, petechiae, lymphadenomegaly, and ataxia) were also clinical signs that may be caused by other hemoparasite infections [19]. Hemopathological findings in these groups of dogs were anemia (low hematocrit and hemoglobin), leukopenia and thrombocytopenia, showing lower values than non-infected dogs, but higher values than dogs with acute or chronic infections. These results are consistent with other reports that suggest that dogs need about 505 days to show normal hematologic values after an acute E. canis infection [20]. It is important to point out that only a very few dogs in this category $(3.3 \% ; 4 / 121)$ had been treated for ehrlichiosis at some time in their lives with doxycycline; therefore, it seems that infection passed unnoticed by owners" instead of "it appears that infection passed unnoticed by owners and that most of the dogs resolved E. canis infections without any medication. However, it cannot be ruled out that dogs continue to be persistently infected with $E$. canis. It has been reported that untreated or inadequate treated dogs can recover clinically, but remain infected with $E$. canis for months or years, showing only abnormal platelet counts and representing a source of infection for other dogs [10] [11]. In these cases, experimental results indicate that the bacteria are located in the spleen, which is the last organ to eliminate this pathogen [21]. Since thrombocyte values were lower than in dogs with acute and non-infected dogs, further studies have to determine if the $E$. canis is still present in tissues or organs (bone marrow and spleen) of subclinically infected dogs and if the infection was resolved without medication. The above could establish future recommendations about the need for medication of dogs with a positive serological result for E. canis and with hemopathological findings, but without DNA positive results and clinical signs, and for the implementation of antigen detection instead of antibody detection techniques [21].

Suggestive clinical signs reported by the owners (bleeding and petechiae), and detected by the veterinarians at the time of sampling (depressive attitude and very pale mucous membranes) of dogs suffering chronic infections were in accordance with reports of the literature [18]. These chronic infections could be due to the fact that only 1 out of 10 dogs was treated with doxycycline, although ineffective. It has been documented that dogs fail to clear the systemic infection with the pathogen [19] and the lack of diagnosis and treatment of these dogs could have an impact on the incidence of this event. Hemopathological findings in these group of dogs were anemia (low hematocrit 
and hemoglobin values) and thrombocytopenia, which is consistent with other reports [11] [14] [22] [23].

Hemopathological findings of dogs with chronic E. canis infection were anemia (low hematocrit and hemoglobin), leukopenia and thrombocytopenia and values were in all cases lower in the group compared with non-infected dogs, and dogs with acute and subclinical infections, due to the longer presence of $E$. canis in blood, and probably other tissues and organs, representing a source of infection [11] [24] and a burden for the organism since the infection was not resolved solely by the dog. Medication of dogs with chronic infection is recommended, and follow-up treatment is necessary to ensure elimination of E. canis from the dog's body.

Suggestive clinical signs reported by the owners (petechiae), and detected by the veterinarians at the time of sampling (petechiae and fever) of dogs suffering from acute infections were in accordance with Gaunt et al. [25], who found fever as the only clinical sign in dogs with experimental E. canis infection between 21 - 35 days p.i. Harrus and Waner [18] stated that hemorrhagic tendencies, like dermal petechiae, were one of the clinical signs presented during the acute phase. Hematological findings were higher hematocrit, hemoglobin and thrombocyte count values than in dogs with chronic infection. This difference is of particular importance since the course of chronic infections may often be complicated and progressively become worse as a result of bone marrow hypoplasia [23]. Anemia was not seen in these dogs although when present it was classically mild to moderate [26]. Platelet count values were also higher than those in non-infected dogs. The acute phase is characterized by megathrombocytosis [8]. Some of these infections could also be recent acute infections since reports on experimental infection in German shepherds using the $E$. canis Oklahoma strain show that the detection of anti-E. canis antibodies was possible two days post infection [27]. Other authors observed seroconversion in Beagles infected with the same Oklahoma strain, occurring between days 5 and 15 p.i. [28].

The present study determined clinical signs and significant hemopathological values of acute, subclinical and chronic E. canis infections in dogs of Costa Rica to guide veterinarians in making treatment decisions. Since serological assays are the only available rapid tests for veterinarians, we recommend treating only those dogs that show suggestive clinical signs and hemopathological values, while the respective PCR is being performed. This is because the clear majority of seropositive dogs (92.6\%) in the present study showed no bacteria in the blood, although significant differences in the values of hematocrit, hemoglobin, MCHC, platelet count, leukocytes, lymphocytes, basophils, and monocytes were detected. Future studies must determine if dogs with subclinical E. canis infection eliminate the agent without any medication, or if they are still persistently infected and need medication; it must also be determined if they will develop the chronic disease at some point in their lives.

\section{Acknowledgements}

This investigation was supported by the Fondo Especial para el Financiamiento de la 
Educación Superior, Consejo Nacional de Rectores (FEES-CONARE) and Vicerrectoría de Investigación, UNA. We wish to thank the city councils of the recreational parks we visited, and the Club de Leones for their support.

\section{References}

[1] Dumler, J.S., Barbet, A.F., Bekker, C.P., et al. (2001) Reorganization of Genera in the Families Rickettsiaceae and Anaplasmataceae in the Order Rickettsiales: Unification of Some Species of Ehrlichia with Anaplasma, Cowdria with Ehrlichia and Ehrlichia with Neorickettsia, Descriptions of Six New Species Combinations and Designation of Ehrlichia equi and "HE Agent" as Subjective Synonyms of Ehrlichia phagocythophila. International Journal of Systematic and Evolutionary Microbiology, 51, 2145-2165.

https://doi.org/10.1099/00207713-51-6-2145

[2] Walker, D. (1996) Rickettsiae. In: Baron, S., Ed., Medical Microbiology, 4th Edition, University of Texas, Texas, Chapter 38.

[3] Mylonakis, M.E., Koutinas, A.F., Billinis, C., et al. (2003) Evaluation of Cytology in the Diagnosis of Acute Canine Monocytic Ehrlichiosis (Ehrlichia canis): A Comparison between Five Methods. Veterinary Microbiology, 91, 197-204.

https://doi.org/10.1016/S0378-1135(02)00298-5

[4] Greene, C.E. (2012) Infectious Diseases of the Dog and the Cat. 4th Edition, Elsevier, Missouri, 227-270.

[5] Neer, M.T. and Harrus, S. (2006) Ehrlichiosis, Neorickettsiosis, Anaplasmosis and Wolbachia Infection. In: Greene, C.E., Ed., Infectious Diseases of the Dog and Cat, Elsevier, Philadelphia, 203-216.

[6] Waner, T., Keysary, A., Bark, H., Sharabani, E. and Harrus, S. (1999) Canine Monocytic Ehrlichiosis-An Overview. Israel Journal of Veterinary Medicine, 54, 103-107.

[7] Dagnone, A.S., Morais, H.S.A. and Vidotto, O. (2001) Erliquiose nos animais e no homem [Ehrlichiosis in Animals and Humans]. Semina: Ciências Agrárias, 22, 191-201.

[8] Waner, T., Harrus, S., Weiss, D.J., Bark, H. and Keysary, A. (1995) Demonstration of Serum Antiplatelet Antibodies in Experimental Acute Canine Ehrlichiosis. Veterinary Immunology and Immunopathology, 48, 177-182. https://doi.org/10.1016/0165-2427(95)05420-B

[9] Codner, E.C. and Farris-Smith, L.L. (1986) Characterization of the Subclinical Phase of Ehrlichiosis in Dogs. Journal of the American Veterinary Medical Association, 189, 47-50.

[10] Harrus, S., Warner, T., Aizenberg, I., Foley, J.E., Poland, A.M. and Bark, H. (1998) Amplification of Ehrlichial DNA from Dogs 34 Months after Infection with Ehrlichia canis. Journal of Clinical Microbiology, 36, 73-76.

[11] Waner, T., Harrus, S., Bark, H., Bogin, E., Avidar, Y. and Keysary, A. (1997) Characterization of the Subclinical Phase of Canine Ehrlichiosis in Experimentally Infected Beagle Dogs. Veterinary Parasitology, 69, 307-317. https://doi.org/10.1016/S0304-4017(96)01130-2

[12] Harrus, S., Kenny, M., Miara, L., Aisenberg, I., Waner, T. and Shaw, S. (2004) Comparison of Simultaneous Splenic Sample PCR with Blood PCR for Diagnosis and Treatment of Experimental Ehrlichia canis Infection. Antimicrobial Agents and Chemotherapy, 48, 4488-4490. https://doi.org/10.1128/AAC.48.11.4488-4490.2004

[13] Meneses, A. (1995) First Report of Canine Ehrlichiosis in Costa Rica. Veterinary Record, 137, 46-47. https://doi.org/10.1136/vr.137.2.46

[14] Romero, L.E., Meneses, A.I., Salazar, L., et al. (2011) First Isolation and Molecular Charac- 
terization of Ehrlichia canis in Costa Rica, Central America. Research in Veterinary Science, 91, 95-97. https://doi.org/10.1016/j.rvsc.2010.07.021

[15] Rojas, A., Rojas, D., Montenegro, V., Gutiérrez, R., Yasur-Landau, D. and Baneth, G. (2014) Vector-Borne Pathogens in Dogs from Costa Rica: First Molecular Description of Babesia vogeli and Hepatozoon canis Infections with a High Prevalence of Monocytic Ehrlichiosis and the Manifestations of Co-Infection. Veterinary Parasitology, 199, 121-128.

https://doi.org/10.1016/j.vetpar.2013.10.027

[16] Barrantes-González, A.V., Jiménez-Rocha, A.E., Romero-Zuñiga, J.J. and Dolz, G. (2016) Serology, Molecular Detection and Risk Factors of Ehrlichia canis Infection in Dogs in Costa Rica. Ticks and Tick-borne Diseases, 7, 1245-1251. https://doi.org/10.1016/j.ttbdis.2016.07.006

[17] Cowell, R.L., Tyler, R.D., Meinkoth, J.H. and DeNicola, D.B. (2008) Hematology of the Dog and Cat. 3rd Edition, Elsevier, Missouri, 20-38.

[18] Harrus, S. and Waner, T. (2011) Diagnosis of Canine Monocytotropic Ehrlichiosis (Ehrlichia canis): An Overview. The Veterinary Journal, 187, 292-296.

https://doi.org/10.1016/j.tvjl.2010.02.001

[19] Nair, A.D.S., Cheng, C., Ganta, C.K., et al. (2016) Comparative Experimental Infection Study in Dogs with Ehrlichia canis, E. chaffeensis, Anaplasma platys and A. phagocytophilum. PloS ONE, 11, e0148239. https://doi.org/10.1371/journal.pone.0148239

[20] McClure, J.C., Crothers, M.L., Schaefer, J.J., et al. (2010) Efficacy of a Doxycycline Treatment Regimen Initiated during Three Different Phases of Experimental Ehrlichiosis. Antimicrobial Agents and Chemotherapy, 12, 5012-5020. https://doi.org/10.1128/AAC.01622-09

[21] Faria, J.L., Dagnone, A.S., Munhoz, T.D., et al. (2010) Ehrlichia canis Morulae and DNA Detection in Whole Blood and Spleen Aspiration Samples. Revista Brasileira de Parasitologia Veterinária, 19, 98-102. https://doi.org/10.4322/rbpv.01902006

[22] Castro, M.B., Machado, R.Z., Aquino, L.P.T., Alessi, A.C. and Costa, M.T. (2004) Experimental Acute Canine Monocytic Ehrlichiosis: Clinicopathological and Immunopathological Findings. Veterinary Parasitology, 119, 73-86. https://doi.org/10.1016/j.vetpar.2003.10.012

[23] Shipov, A., Klement, E., Reuveni-Tager, L., Waner, T. and Harrus, S. (2008) Prognostic Indicators for Canine Monocytic Ehrlichiosis. Veterinary Parasitology, 153, 131-138. https://doi.org/10.1016/j.vetpar.2008.01.009

[24] Harrus, S., Waner, T., Keysary, A., Aroch, I., Voet, H. and Bark, H. (1998) Investigation of Splenic Function in Canine Monocytic Ehrlichiosis. Veterinary Immunology and Immunopathology, 62: 15-27. https://doi.org/10.1016/S0165-2427(97)00127-X

[25] Gaunt, S.D., Beall, M.J., Stillman, B.A., et al. (2010) Experimental Infection and Co-Infection of Dogs with Anaplasma platys and Ehrlichia canis: Hematologic, Serologic and Molecular Findings. Parasites \& Vectors, 3, 33. https://doi.org/10.1186/1756-3305-3-33

[26] Waner, T. and Harrus, S. (2000) Anemia of Inflammatory disease. In: Feldman, B.F., Zinkl, J.G. and Jain, N.C., Eds., Schalm's Veterinary Hematology, Williams \& Wilkins, Philadelphia, 212-215.

[27] Munhoz, T.D., Faria, J.L., Vargas-Hérnandez, G., et al. (2012) Experimental Ehrlichia canis Infection Changes Acute-Phase Proteins. Revista Brasileira de Parasitologia Veterinária, 21, 206-212. https://doi.org/10.1590/S1984-29612012000300006

[28] Shimada, T., Ishida, Y., Shimizu, M., et al. (2002) Monitoring C-Reactive Protein in Beagle Dogs Experimentally Inoculated with Ehrlichia canis. Veterinary Research Communications, 26, 171-177. https://doi.org/10.1023/A:1015290903332 
Submit or recommend next manuscript to SCIRP and we will provide best service for you:

Accepting pre-submission inquiries through Email, Facebook, LinkedIn, Twitter, etc. A wide selection of journals (inclusive of 9 subjects, more than 200 journals)

Providing 24-hour high-quality service

User-friendly online submission system

Fair and swift peer-review system

Efficient typesetting and proofreading procedure

Display of the result of downloads and visits, as well as the number of cited articles

Maximum dissemination of your research work

Submit your manuscript at: http://papersubmission.scirp.org/

Or contact ojvm@scirp.org 